\title{
On the Theory of Evolution Versus the Concept of Evolution: Three Observations
}

\author{
Guillermo Paz-y-Miño C. • Avelina Espinosa
}

Published online: 15 December 2010

(C) Springer Science+Business Media, LLC 2010

G. Paz-y-Miño C

Department of Biology, University of Massachusetts Dartmouth, 285 Old Westport Road,

North Dartmouth, MA 02747-2300, USA

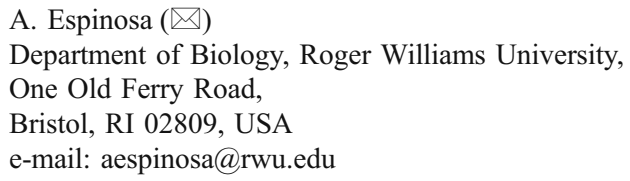

\begin{abstract}
Here we address three misconceptions stated by Rice et al. in their observations of our article Paz-y-Miño and Espinosa (Evo Edu Outreach 2:655-675, 2009), published in this journal. The five authors titled their note "The Theory of Evolution is Not an Explanation for the Origin of Life." First, we argue that it is fallacious to believe that because the formulation of the theory of evolution, as conceived in the 1800 s, did not include an explanation for the origin of life, nor of the universe, the concept of evolution would not allow us to hypothesize the possible beginnings of life and its connections to the cosmos. Not only Stanley Miller's experiments of 1953 led scientists to envision a continuum from the inorganic world to the origin and diversification of life, but also Darwin's own writings of 1871. Second, to dismiss the notion of Rice et al. that evolution does not provide explanations concerning the universe or the cosmos, we identify compelling scientific discussions on the topics: Zaikowski et al. (Evo Edu Outreach 1:65-73, 2008), Krauss (Evo Edu Outreach 3:193-197, 2010), Peretó et al. (Orig Life Evol Biosph 39:395-406, 2009) and Follmann and Brownson (Naturwissenschaften 96:1265-1292, 2009). Third, although we acknowledge that the term Darwinism may not be inclusive of all new discoveries in evolution, and also that creationists and Intelligent Designers hijack the term to portray evolution as ideology, we demonstrate that there is no statistical evidence suggesting that the word
\end{abstract}

Darwinism interferes with public acceptance of evolution, nor does the inclusion of the origin of life or the universe within the concept of evolution. We examine the epistemological and empirical distinction between the theory of evolution and the concept of evolution and conclude that, although the distinction is important, it should not compromise scientific logic.

Keywords Belief. Cosmic evolution · Darwinism · Origin of life $\cdot$ Science education

It is important to make a distinction between the theory of evolution and the concept of evolution, but without compromising logic. As scientific theory (Greek theoria), evolution provides naturalistic explanations of empirical observations, it organizes them in a comprehensive system with central and auxiliary hypotheses. From the epistemological perspective (Greek episteme, epistemology $=$ theory of knowledge), the theory of evolution encompasses the nature and scope of knowledge about the phenomenon of evolution (=what really happens), including the chronological discoveries by naturalists and scientists during the development of our cumulative understanding of how evolution works. Scholars call the latter "theory of evolution," whose epistemological beginning is attributed to the mid and late 1800s, and to Charles Darwin and Alfred R. Wallace as main contributors to the conceptualization of evolution at the mechanistic level (=natural selection). But the phenomenon of evolution is ongoing, precedes Darwin and Wallace in billions of years, and it shall continue, with comparable magnitude, in time and space. The concept of evolution, therefore, is about the occurrence of evolution (i.e., the aggregation of matter, the emergence of organic compounds from simpler molecules, the formation of self-replicating macro-molecules, the encasing of chemical reactions within the boundaries of 
lipid-layered membranes, the formation of cells and their reproduction and differentiation, and the diversification of uni- and multi-cellular life) and it helps us understand and represent cognitively - via mental symbolism and abstraction - the reality of evolution. Our understanding of evolution improves with new discoveries, but the reality of evolution continues to exist regardless of our awareness and level of understanding of it.

When examining our article Acceptance of Evolution Increases with Student Academic Level: A Comparison Between a Secular and a Religious College (Paz-y-Miño C. and Espinosa 2009), in which we demonstrate variability in patterns of acceptance of evolution at secular versus religious institutions as a function of educational attainment, five authors from Iowa State University (Rice et al. 2010) make three observations to which we respond as follows:

Observation 1 Rice et al. title their note The Theory of Evolution is Not an Explanation for the Origin of Life and state that "the theory of evolution, both currently and as first conceived by Darwin and Wallace, neither provides, nor requires, an explanation for the origin of life." As Gould (1987) noted over two decades ago, 'Evolution, in fact, is not the study of origin at all... Evolution studies the pathways and mechanisms of organic change after the origin of life." Rice et al. fail at making a conceptual distinction between the theory of evolution and the concept of evolution (above). Although from the epistemological perspective Rice et al.'s assertions may be valid (i.e., Darwin did not address the origin of life, nor of the universe, in The Origin of Species of 1859, but see below), from the empirical-reality viewpoint the origin of life is inconceivable without a prior evolutionary process or explanation. It is fallacious to believe that because "the theory of evolution is not an explanation for the origin of life" (Rice et al. 2010), the concept of evolution would not allow us to hypothesize and test the possible beginnings of life (see Lazcano and Peretó 2010 for a specific criticism of the position of Rice et al. concerning this point). The experiments of Stanley Miller (1953) from the 1950s did precisely that: he tested the hypothesis that simple organic molecules (amino acids), precursors of life, could have been generated in a lifeless, primitive Earth (the significance of these experiments has been discussed in detail; Bada and Lazcano 2003; Johnson et al. 2008; Lazcano and Bada 2008). Despite the simplicity of Miller's approach (see Lazcano and Bada 2008), his findings allowed scientists to envision an obvious continuum from the inorganic world to the chemical organic bloom, and to the origin and diversification of life from ordinary matter (Follmann and Brownson 2009; Lazcano 2010). The concept of evolution was the foundation of Miller's scientific thinking and laboratory logic, and his findings as a "pioneer prebiotic chemist" enriched the "body of knowledge" called the theory of evolution. But the link of life to primordial chemistry was already evident to Darwin, who in 1871 corresponded with Joseph Dalton Hooker: "it is often said that all the conditions for the first production of a living being are now present, which could ever have been present. But if (and oh what a big if) we could conceive in some warm little pond with all sort of ammonia and phosphoric salts, -light, heat, electricity present, that a protein compound was chemically formed, ready to undergo still more complex changes, at the present such matter would be instantly devoured, or absorbed, which would not have been the case before living creatures were formed." (Darwin 1887; for analysis of this correspondence see Peretó et al. 2009). A recent review (Schrum et al. 2010) explores such plausible scenarios for the transition from prebiotic chemistry to simple biology, including the chemical assemblies capable of "Darwinian evolution" during the origin of cellular life.

Rice et al. state that "wrongly confusing the initial origin of life with biological evolution interferes with students' acceptance of biological evolution in at least two ways: (a) students often hold more tightly to a supernatural account for the origin of life than they do to a supernatural account for how the diversity of life arose, and (b) because no compelling natural explanation exists for how life originated, students also reject biological evolution." This absurdity implies that because students-supposedly-accept supernatural causation about the origin of life more than they accept it for the diversification of life, we ought to perpetuate ignorance in the science class, or endorse partial falsehood, by avoiding the topic "origin of life," which is a legitimate component of the concept of evolution (above and below), and address evolution "only after life began" to secure, in this manner, students' sympathy for evolution. This unfortunate position contradicts conceptual work and empirical research about attitudes toward evolution, including the data published in our article (Paz-y-Miño C. and Espinosa 2009), to which Rice et al. refer. For example, according to the way college students conceive evolution, $76 \%$ of them value the factual explanation evolution provides about the origin of life and its place in the universe, $83 \%$ prefer science courses where human evolution is discussed, and $77 \%$ welcome questions concerning evolution in all science exams (mean rounded up values; for detailed statistics see Paz-y-Miño C. and Espinosa 2009). In a recent study (Paz-y-Miño C. and Espinosa 2010), we report that $82 \%$ of college students (and university professors, $90 \% \mathrm{PhD}$ holders in 40 disciplines, including biology, at 35 institutions) consider the following definition of evolution as true: gradual process by which the universe changes, it includes the origin of life, its diversification and the synergistic phenomena resulting 
from the interaction between life and the environment. Regardless of the academic distinction between theory of evolution and concept of evolution (above), or the arguable content of this narrative, the students (and professors) think of evolution as described in the statement (see Observation 2 , below, for more on this topic).

In contrast to the belief of Rice et al. that by confusing the origin of life with biological evolution (something clear to us) educators interfere with acceptance of evolution, scholars have demonstrated that three measurable factors determine an individual's acceptance of evolution (Bishop and Anderson 1999; Downie and Barron 2000; Trani 2004; Paz-y-Miño C. and Espinosa 2009 and 2010, but see Miller et al. 2006; Nadelson and Sinatra 2009): personal religious convictions, understanding the essence of science (=method to explore reality), and familiarity with the processes and forces of change in organisms (=evolution). In fact, acceptance of evolution increases with science/evolution literacy and decreases with religiosity, as follows: Public acceptance of evolution in the US increases from the highschool $(20 / 21 \%)$, some-college $(32 / 41 \%)$, college graduate $(52 / 53 \%)$ to the post-graduate $(65 / 74 \%)$ levels (Brumfield 2005; The Gallup Poll 2009), reaching the highest score among university professors (97\%, Paz-y-Miño C. and Espinosa 2010). Negative attitudes toward evolution in the US reside in specific variables: religious beliefs, pro-life beliefs, and political ideology account for most of the variance against evolutionary views (total nine independent variables), which differ distinctly between the US $\left(R^{2}=0.46\right.$ total effects) and Europe ( $R^{2}=0.18$ total effects; Miller et al. 2006; see The Pew Forum On Religion \& Public Life 2008) for detailed statistics on the relationship between religious affiliations and pro-life beliefs, political ideology and evolution); conservative republicans in the US accept evolution less than progressive liberals and independents (30\% versus 60\%, respectively; The Gallup Poll 2007); and frequency of religious practices correlates negatively with acceptance of evolution: $24 \%$ among weekly churchgoers versus $71 \%$ for seldom or never (The Gallup Poll 2007).

We have proposed that if attitudes toward evolution by both the general public and highly educated audiences correlate, ultimately, with understanding of science/evolution and degree of religiosity/political ideology (positive and negative association of variables, respectively, above), it follows that robust science education combined with vigorous public debate - where scientific knowledge versus popular belief are constantly discussed-shall increase acceptance of naturalistic rationalism and decrease the negative impact of creationism on society's evolution literacy (Paz-y-Miño C. and Espinosa 2010).

Observation 2 Rice et al. state that "biological evolution should not be confused with evolutionary processes outside the realm of biology as it does not provide explanations concerning the "universe' or the "cosmos." The broad concept of evolution, as we use it in our article and which is not restricted to biology (i.e., evolution is a gradual process by which the universe changes, it includes the origin of life, its diversification and the synergistic phenomena resulting from the interaction between life and the environment; Pazy-Miño C. and Espinosa 2009), dismisses this assertion because the phenomenon of 'biological evolution' takes place in the cosmos, our solar system and-as documented so far-on Earth, thus governed by the laws of the universe. Significant articles, published in Evolution: Education and Outreach and other prestigious journals, analyze this holistic view of evolution and their titles are compelling: Science and the Concept of Evolution: From the Big Bang to the Origin and Evolution of Life (Zaikowski et al. 2008), Cosmic Evolution (Krauss 2010), Charles Darwin and the Origin of Life (Peretó et al. 2009), and Darwin's Warm Little Pond Revisited: From Molecules to the Origin of Life (Follmann and Brownson 2009). By integrating physics, chemistry, and biology, modern scientists and education scholars secure an interdisciplinary approach to understanding the evolutionary process, beginning with the formation of the universe and emergence of the simplest elements, and continuing toward more complex elements and molecules, including prebiotic compounds and, ultimately, the molecular diversity and complexity of today's living organisms (see Zaikowski et al. 2008 for an example of a multi-disciplinary approach to addressing these topics in the science class; in addition, at Arizona State University, LM Krauss offers the course PHY394 Origins: From the Big Bang to Life on Earth and Beyond, see references for website link). Indeed, biological evolution "requires the products of cosmic evolution" or the raw materials to build life, which are the elements first formed in the cores of stars (Krauss 2010). Physicist Lawrence M. Krauss acknowledges the work of "natural selection" at the cosmic scale and emphasizes that "our existence in our universe could...merely be a selection effect, turning evolution into a cosmic phenomenon and not merely a biological and terrestrial one...the starting point of biological evolution occurred long before the first amino acids arose in interstellar space" (Krauss 2010). It is, therefore, another absurdity to believe, as Rice et al. apparently do, that because the historical advent of the theory of evolution (sensu stricto, above), as conceived by Darwin and Wallace, did not include the origin of life or the universe, we cannot apply the concept of evolution to find the connection between the "origin of species" with events preceding the origin of life, or organic molecular diversity, or prebiotic compounds, or complex and simple elements or, at first, the formation of the universe itself. We are connected biologically to each other and all forms of life, chemically to the 
planet, and atomically to the cosmos (paraphrasing astrophysicist Neil deGrasse Tyson 2007). And we think that the distinction between cosmic evolution and biological evolution might be as artificial as the distinction between microevolution (i.e., small changes over short time spans involving minor genetic and phenotypic modifications) and macroevolution (i.e., major changes over long periods of time involving many traits and significant transformations like speciation). Here we paraphrase Zimmer (2001): for those who only accept microevolution (e.g., creationists), Zimmer gives them macroevolution "for free," since both are interdependent. Analogously, for those who only accept "biological evolution" as the single legitimate component of the concept of evolution, it follows that they should consider that the emergence of life is intrinsically linked to cosmic evolution.

Observation 3 Rice et al. indicate that "the term 'Darwinism' is most commonly used by the opponents of evolution to trivialize the theory as being merely the idea of one person or to attempt to place the theory on par with other 'isms' e.g., Protestantism. This reinforces the view held by some members of the public that evolution (and science in general) is merely a cult or type of religion." This point requires clarification: the concept of evolution is rejected by $60-65 \%$ of the American public (Brumfield 2005; Miller et al. 2006) because it challenges creationists' views, which are consistent with poor understanding of science/evolution and high levels of religiosity (variables examined in Observation 1, above). The data, again, contradicts the anecdotal opinion of Rice et al. In fact, 53\% of Americans who identify correctly the name of Charles Darwin with the theory of evolution also accept evolution; $29 \%$ of those who correctly link Darwin with the theory do not accept evolution, and the remaining $18 \%$ have no opinion. Among those that incorrectly identify Darwin with a different theory, 29\% accept evolution, 30\% do not accept it, and $40 \%$ have no opinion. Finally, of those responders that are unaware of any connection between Darwin and the theory of evolution, $18 \%$ accept evolution, $17 \%$ do not accept it, and $64 \%$ have no opinion (The Gallup Poll 2009). The data above demonstrates that the more familiarity with the name of Darwin, the higher the acceptance of evolution; and the more ignorance about the connection between Darwin and the theory, the higher the lack of opinion in any direction. Moreover, correct identification of "Darwin with the theory of evolution by means of natural selection" is, of course, correlated with higher levels of education: from high school $(31 \%)$, some college $(63 \%)$, college graduate $(82 \%)$, to the postgraduate $(86 \%)$ levels (The Gallup Poll 2009). Although we do acknowledge that the term Darwinism may not be inclusive of all modern discoveries, in multiple scientific disciplines, which now contribute to evolutionary thinking, and also that creationists and Intelligent Design followers have hijacked the term to portray evolution as a dangerous ideology (Scott and Branch 2009), there is no current statistical evidence suggesting that the word Darwinism interferes with public acceptance of evolution (The Gallup Poll 2009).

We concur with Rice et al. in that "the propagation of misconceptions about the theory of biological evolution must be addressed whenever and wherever they are encountered" and that "the scientific community currently has access to far more data to support Darwin's (and Wallace's) seminal idea than when he first published on how new species arise from a common ancestor." Indeed, the evidence in support for the obvious connection between the "origin of the species" and the formation of the cosmos, via the laws of physics, chemistry and the gradual accumulation of biological complexity, from the atomic to the molecular to the organismic levels, is growing — at least —or compelling - at most (Zaikowski et al. 2008; Krauss 2010), despite the lack of detailed understanding about the origin of life. And we encourage Rice et al. to re-examine our article in its original context, as well as re-explore the famous passage from Darwin's writing (1859): "There is grandeur in this view of life, with its several powers, having been originally breathed into a few forms or into one; and that, whilst this planet has gone cycling on according to the fixed law of gravity, from so simple a beginning endless forms most beautiful and most wonderful have been, and are being, evolved." It was Darwin who so Darwinianly sensed the connection between life and the laws of Earth.

Lazcano and Peretó (2010) consider our statement "evolution is the language of the cosmos" (Paz-y-Miño C. and Espinosa 2009) to be a "wonderful metaphor." We used it to highlight the gradual change of matter in space and time that, occasionally, can trigger the "events leading to life" under favorable conditions such as those of our planet. But what is really wonderful is the concept of "cosmic evolution" embraced by physicist Lawrence M. Krauss (2010) to elegantly explain our existence in the universe as an interstellar phenomenon.

Acknowledgments Two reviewers provided comments and formulated fascinating questions that helped us improve our discussion.

\section{References}

Bada JL, Lazcano A. Prebiotic soup-revisiting the Miller experiment. Science. 2003;300:745-6.

Bishop BA, Anderson CW. Student conceptions of natural selection and its role in evolution. J Res Sci Teach. 1999;27:415-27.

Brumfield G. Who has designs on your students' minds? Nature. 2005;434:1062-5. 
Darwin C. On the origin of species by means of natural selection, or the preservation of favoured races in the struggle for life. 1st ed. London: John Murray; 1859.

Darwin F, editor. The life and letters of Charles Darwin, including an autobiographical chapter. 3 Vol. London: John Murray; 1887.

deGrasse Tyson N. Neil deGrasse Tyson's top ten favorite facts about the universe. The Washington Post. Available at: http://www. washingtonpost.com/wp-dyn/content/article/2007/12/14/ AR2007121400571.html; 2007. Accessed on Nov. 272010.

Downie JR, Barron NJ. Evolution and religion: attitudes of Scottish first year biology and medical students to the teaching of evolutionary biology. J Biol Educ. 2000;34:140-6.

Follmann H, Brownson C. Darwin's warm little pond revisited: from molecules to the origin of life. Naturwissenschaften. 2009;96:1265-92.

Gould SJ. Justice Scalia's misunderstanding. Nat Hist. 1987;96:14-21.

Johnson AP, Cleave HJ, Dworkin JP, Glavin DP, Lazcano A, Bada JL. The Miller volcanic spark discharge experiment. Science. 2008;322:404.

Krauss LM. Cosmic evolution. Evo Edu Outreach. 2010;3:193-7.

Lazcano A. Historical development of origins research. Cold Spring Harb Perspect Biol. 2010. doi:10.1101/cshperspect.a002089.

Lazcano A, Bada JL. Stanley L. Miller (1930-2007): reflections and remembrances. Orig Life Evol Biosph. 2008;38:373-81.

Lazcano A, Peretó J. Should the teaching of biological evolution include the origin of life? Evo Edu Outreach. 2010;3:661-67.

Miller SL. A production of amino acids under possible primitive Earth conditions. Science. 1953;117:528.

Miller JD, Scott EC, Okamoto S. Public acceptance of evolution. Science. 2006;313:765-6.

Nadelson LS, Sinatra GM. Educational professionals' knowledge and acceptance of evolution. Evol Psychol. 2009;7:490-516.

Paz-y-Miño CG, Espinosa A. Acceptance of evolution increases with student academic level: a comparison between a secular and a religious college. Evo Edu Outreach. 2009;2:655-75.
Paz-y-Miño CG, Espinosa A. New England faculty and college students differ in their views about evolution, creationism, Intelligent Design and religiosity. Evo Edu Outreach; 2010 (in press).

Peretó J, Bada JL, Lazcano A. Charles Darwin and the origin of life. Orig Life Evol Biosph. 2009;39:395-406.

PHY394 Origins: From the Big Bang to life on earth and beyond. Program origins at Arizona State University. Exploring questions at the edge of knowledge: from the Universe to humanity: http:// origins.asu.edu/index.php. Accessed on Nov. 272010.

Rice JW, Warner DA, Kelly CD, Clough MP, Colbert JT. The theory of evolution is not an explanation for the origin of life. Evo Edu Outreach. 2010;3:141-2.

Schrum JP, Zhu TF, Szostak JW. The origins of cellular life. Cold Spring Harb Perspect Biol. 2010. doi:10.1101/cshperspect.a002212.

Scott EC, Branch G. Don't call it "Darwinism". Evo Edu Outreach. 2009;2:90-4.

The Gallup Poll. Majority of republicans doubt theory of evolution. Available at: http://www.gallup.com/poll/27847/ Majority-Republicans-Doubt-Theory-Evolution.aspx; 2007. Accessed on Nov. 272010

The Gallup Poll. On Darwin's birthday, only 4 in 10 believe in evolution. Available at: http://www.gallup.com/poll/114544/Darwin-BirthdayBelieve-Evolution.aspx; 2009. Accessed on Nov. 272010.

The Pew Forum On Religion \& Public Life. US religious landscape survey-religious beliefs and practices: diverse and politically relevant. Washington DC. Available at: http://religions.pewforum. org/pdf/report-religious-landscape-study-full.pdf; 2008. Accessed on Nov. 272010.

Trani R. I won't teach evolution; it's against my religion. And now for the rest of the story. Am Biol Teach. 2004;66:419-27.

Zaikowski L, Wilkens RT, Fisher K. Science and the concept of evolution: from the big bang to the origin and evolution of life. Evo Edu Outreach. 2008;1:65-73.

Zimmer C. Evolution, the triumph of an idea. New York: Harper Collins; 2001. 